\title{
INFORMATION SYSTEM OF BLOOD NEEDS STOCK ON THE INDONESIAN RED CROSS USING WEIGHTED MOVING AVERAGE METHOD
}

\author{
Arif Rakhman $^{1)}$, Yerry Febrian Sabanise ${ }^{2)}$ \\ Politeknik Harapan Bersama Tegal \\ Jl. Mataram No. 9 Kota Tegal \\ Email : ${ }^{1}$ cakrakirana7@gmail.com, ${ }^{2}$ yerryfebrian@gmail.com
}

\begin{abstract}
The Indonesian Red Cross (PMI) is a national national association organization in Indonesia engaged in the field of social, humanitarian and health. The logistics section of the Blood Transfusion Unit (UTD) is a warehouse where blood stock is store in, out, or destroyed blood. The importance of blood availability at requires The Indonesian Red Cross requires The Indonesian Red Cross to always maintain the availaibility of blood to meet the need for blood tranfusion . the application of prediction as an effort to control blood supply is considered important. This is needed to minimize the amount of ordering and storing blood that must be borne by The Indonesian Red Cross. For this reson, a precise prediction method is needed in order to produce an accurate estimate of blood supply. In this study the prediction of blood is done using the Weigthed Moving Average (WMA) method, because the patern of stock data and blood demand owned by The Indonesian Red Cross follows the trend data pattern. Comparison of the smallest error value between the $3^{\text {th }}$-month WMA period and $6^{\text {th }}$-month WMA selected to be the result of focasting. The results of the average error value (MAD, MSE, and MAPE) show a period of 6 months has the smallest value, although there is a decline in blood type $A B$, but the difference in the ratio of error values in goldar $A B$ is not too far. This happens because donors or requests for $A B$ goldar are not too many.
\end{abstract}

Keywords : Weighted Moving Averages, forecasting, The Indonesian Red Cross, blood type

\section{Pendahuluan}

Pemenuhan ketersediaan darah merupakan suatu hal yang sangat penting. Stok darah yang terlalu menumpuk dapat mengakibatkan kerugian yang signifikan, karena darah memiliki batas tenggang untuk digunakan . sebaliknya, jika stok darah terlalu sedikit akan berakibat tidak terpenuhinya kebutuhan darah untuk masyarakat dan membuat kepercayaaan pada pelayanan PMI menjadi menurun.PMI masih sering mengalami kekurangan persediaan darah sehingga pada beberapa kasus sering mengakibatkan hilangnya nyawa masyarakat karena kehabisan darah. Terjadinya bencana alam yang tiba-tiba juga berdampak pada kebutuhan darah yang banyak dana mendesak dan membuat PMI membutuhkan donasi yang lebih.

Berbagai upaya telah dilakukan PMI dalam memnuhi stok darah, salah satunya dengan cara melakukan program doroh darah di berbagai macam tempat dan event tertentu, seperti program donor darah di sekolah, kantor pemerintah, dan universitas yang melibatkan banyak warga di sekitar area tersebut, tentunya dengan melakukan uji tes kesehatan terlebih dahulu pada acalon pendonor. 
Prediksi terhadap persediaan darah sangat diperlukan untuk mengatasi permasalahan terkait stok darah dan banyaknya permintaan darah[1]. Prediksi diharapkan dapat memperkecil adanya kelebihan dan kekurangan stok darah. Penerapan prediksi sebagai salah satu upaya mengontrol persediaan darah dinilai penting. Hal itu diperlukan untuk meminimalkan jumlah pemesanan dan penyimpanan darah yang harus ditanggung PMI [10]. Untuk itu, diperukan suatu metode prediksi yang tepat agar dpat menghasilkan sebuah perkiraan yang akurat terhadap persediaan darah. Pada penelitian ini prediksi kebutuhan darah dilakukan dengan menggunakan metode Weighted Moving Average (WMA), karena pola data stok dan permintaan daraha yang dimiliki PMI mengikuti pola data trend. Prediksi jumlah order oleh PMI Kota Tegal menggunkan data masa lalau selama 1 tahun, yaitu periode 2018. Penggunaaan metode WMA pada prediksi jumlah penerimaan darah dan jumlah pengeluaran darah diharapkan mampu menjadi solusi atas permasalahan persediaan darah dengan meramalkan jumlah darh PMI pada bulan selanjutnya.

Jenis peramalan berdasarkan metode peramalan yang digunakan, peramalan dibedakan menjadi metode kualitatif dan metode kuantitatif[11]. Metode kualitatif merupakan metode peramalan yang tidak menggunkan data historis masa lalu, lebih didasarkan pada intuisi. Metode kuantitatif merupakan metode peramalan yang menggunakan data historis masa lalu, memanipulasi data historis yang tersedia secara memadai dan tanpa intuisi, metode ini umumnya didasarkan pada analisa statik. peramalan kuantitatif dapat diterapkan bila tiga kondisi terpenuhi[10], yaitu informasi mengenai keadaan waktu yang lalau tersedia, informasi itu dapat dikuantitatifkan dalam bentuk data numerik, dan dapat diasumsikan bahwa beberapa aspek dari pola di waktu yang lalu akan berlanjut ke waktu yang akan datang. Metode yang termasuk ke dalam metode kuantitatif, salah satunya adalah metode rata-rata bergerak (Moving Average).

Penelitian yang berjudul Sistem Peramalan Untuk Pengadaan Material Unit Injection Di PT. XYZ yang dilakukan oleh Ade Abdul Gofur dan Utami Dewi Widianti dari Universitas Komputer Indonesia. Penelitian ini menjelaskan tentang implementasi metode WMA berdasarkan nilai galat dan Mean Square Error (MSE) untuk memprediksi jumlah pemakaian dari setiap jenis material yang kemudian dijadikan sebagai pembuatan perencanaan pemesanan material. Nilai galat dan MSE dipilih untuk menguji metode karena menghasilkan nilai terkecil dibandingkan dengan metode lain yang termasuk ke dalam metode model time series[3].

Penelitian kedua yang berjudul Pengembangan Sistem Informasi Penjualan Dan Peramalan Jual Beli Menggunakan Metode Weighted Moving Average (Studi Kasus Toko Emas Maju Sari Kota Malang) yang dilakukan oleh Hendra Pradibta dan Aulia Umar Nur Al Saffa dari Politeknik Negeri Malang. Penelitian ini menjelaskan implementasi dari metode WMA pada sistem informasi penjualan yang akan memprediksi jumlah stok barang untuk bulan berikutnya berdasarkan transaksi jual beli bulan-bulan sebelumnya, sehingga pemilik toko tidak perlu membeli stok barang dengan semua modal yang didapat hanya menambah stok barang dengan menggunakan prediksi dari data penjualan bulan-bulan sebelumnya. Mean Absolute Deviation (MAD) dan Mean Absolute Percent (MAPE) dipilih untuk menguji tingkat galat dari prediksi menggunakan WMA [5]. 


\section{Metode Penelitian}

Metode yang dipilih dalam penelitian ini adalah Weight Moving Average karena metode ini memiliki, kelebihan dibanding metode lain yang sejenis[3]. Selain perhitungannya yang sederhana menjelaskan bahwa :

“Teknik Weigt Moving Average diberikan bobot yang berbeda untuk setiap data histori masa lalu yang tersedia, dengan asumsi bahwa data historis yang paling terakhir atau terbaru akan memiliki bobot lebih besar dibandingkan dengan data historis yang lain, Karen data yang paling terakhir atau terbaru merupakan data yang paling relevan untuk peramalan [9]."

Rumus yang digunakan dalam sistem peramalan untuk jumlah stok darah menggunkan metode Weighted Moving Average [4], yaitu :

A. Rumus dari metode Weight Moving Average (WMA) adalah sebagai berikut :

\section{WMA $=\left(\sum(\right.$ Dt $*$ Bobot $\left.)\right) /\left(\sum\right.$ Bobot $)$}

Keterangan :

Dt : data aktual pada periode $\mathrm{t}$

Bobot : bobot yang diberikan untuk setiap bulan

B. Rumus menghirung galat adalah sebagai berikut

\section{$\mathbf{E t}=\mathbf{X t}-\mathbf{F t}$}

Keterangan :

Et : Nilai galat

$\mathrm{Xt}$ : data aktual pada periode ke $\mathrm{t}$

$\mathrm{Ft}$ : data ramalan pada periode ke $\mathrm{t}$

C. Rumus menghitung Mean Square Error (MSE) adalah sebagai berikut :

\section{MSE $=\sum \mathbf{E t} 2 / \mathbf{n}$}

Keterangan :

Et2 : Nilai galat kuadrat

$\mathrm{n}$ : banyak data

D. Rumus menghitung Mean Absolute Deviantion (MAD) adalah sebagai berikut :

$$
\mathbf{M A D}=\sum|\mathbf{E t}| / \mathbf{n}
$$

Keterangan :

Et : nilai galat absolut

$\mathrm{n}$ : banyak data

E. Rumus menghitung Mean Absolut Persentage Error (MAPE) adalah sebagai berikut :

\section{MAPE $=\left(\sum|\mathbf{E t} / \mathbf{X t}| \mathbf{x} 100\right) / \mathbf{n}$}

Keterangan :

Et : Nilai galat

$\mathrm{Xt}$ : data aktual pada period eke $\mathrm{t}$ 
$\mathrm{n}$ : banyak data

Berdasarkan permasalahan yang dialami oleh PMI mengenai prediksi jumlah darah masuk dan darah keluar yang digunakan untuk menanggulangi adanya kelebihan dan kekurangan stok darah, maka penelitian menerapkan prediksi dengan metode Weighted Moving Average.

Penerapan metode Weighted Moving Average dipilih berdasarkan pola data yang dimiliki oleh PMI, yaitu pola data trend. Penggunaan metode ini sangat tepat karena mengolah data yang bersifat non stasioner. Metode WMA tepat untuk digunakan pada objek yang memiliki data 3 tahun[7]. Sehingga pengunaan metode ini menjadi sebuah solusi dalam pemecahan permasalahan penentuan jumlah stok darah untuk mengontrol jumlah stok darah yang dimiliki di masa yang akan dating[8]. Prosedur permalannya ditampilkan pada diagram alir berikut ini :

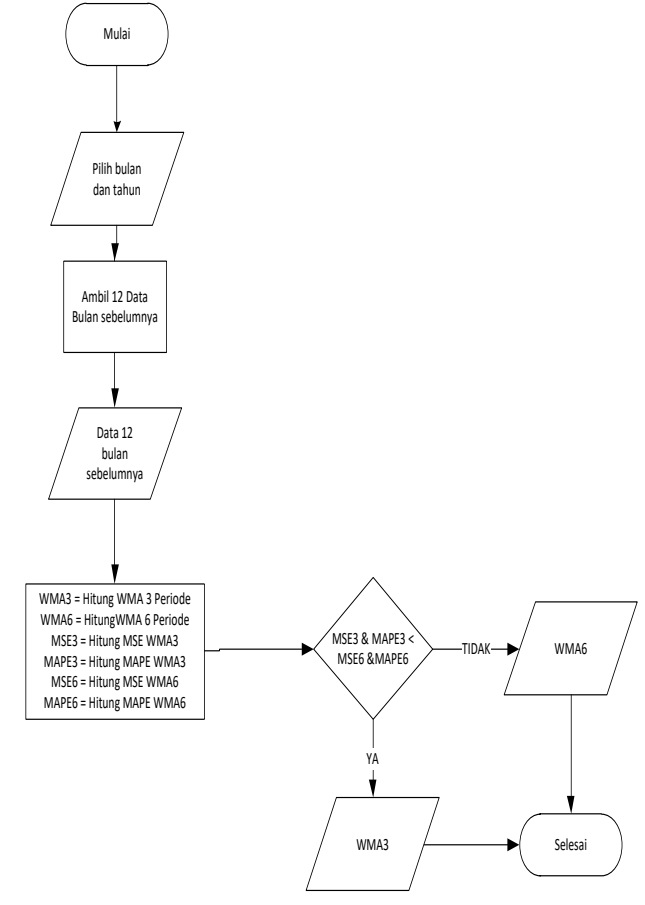

Gambar 1. Diagram alir peramalan stok darah

\section{Hasil Dan Pembahasan}

Periode Peramalan WMA 3 bulan

$$
\begin{array}{ll}
\text { WMA }_{\text {Desember } 2018} & =((296 \times 1)+(394 \times 2)+(246 \times 3)) /(1+2+3) \\
(\text { Peramalan }) & =(296+788+738) / 6 \\
& =1822 / 6 \\
& =303,67 \\
\text { Et (Error) } & =338-303,67 \\
& =34,33 \\
\mathrm{AD} & =|34,33| \\
\mathrm{SE} & =34,33 \\
& =34,33^{2} \\
& =1178,78
\end{array}
$$


$\operatorname{APE}(\%) \quad=|34,33 / 338| \times 100$

$=|0,10156| \times 100$

$=10,16$

- Untuk nilai MAD adalah rata-rata semua nilai AD.

- Untuk nilai MSE adalah rata-rata semua nilai SE.

- Untuk nilai MAPE adalah rata-rata semua nilai APE

- Periode Peramalan WMA 6 bulan

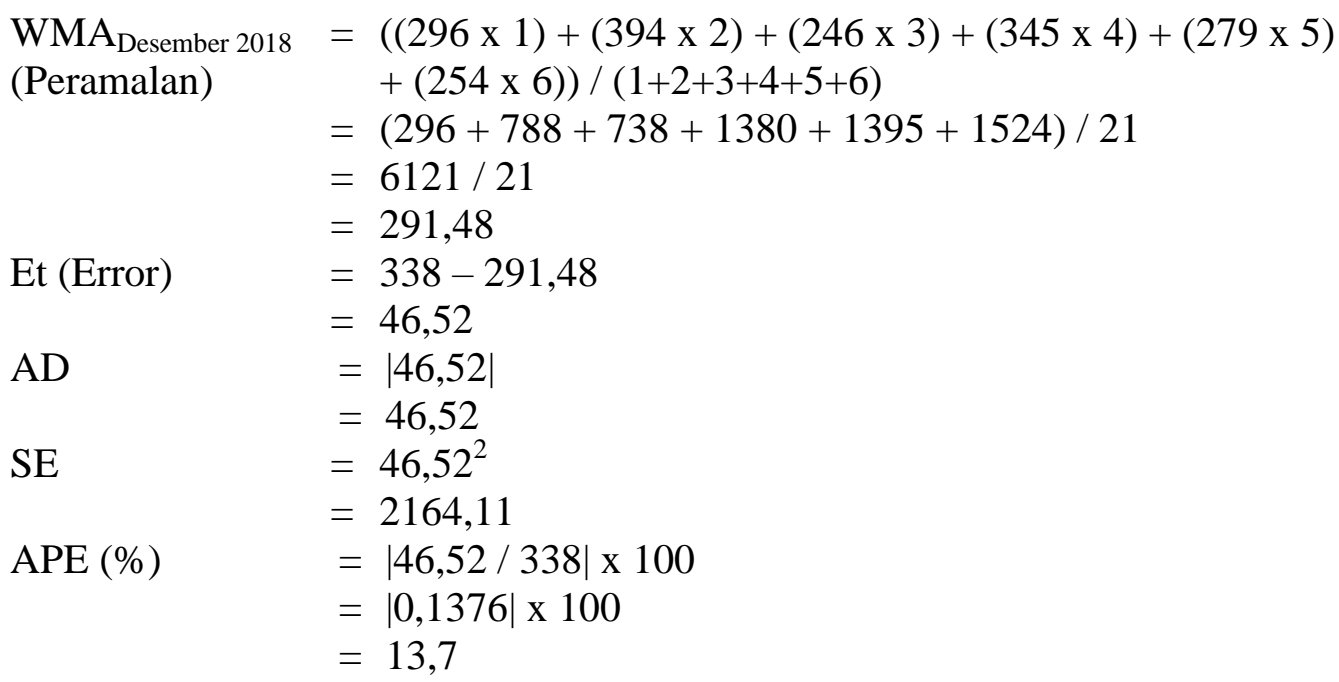

- Untuk nilai MAD adalah rata-rata semua nilai AD.

- Untuk nilai MSE adalah rata-rata semua nilai SE.

- Untuk nilai MAPE adalah rata-rata semua nilai APE

A. Petunjuk pengoperasian program untuk user / admin adalah sebagai berikut :

1. Buka web browser lalu ketik www.sisdar.com nanti akan muncul tampilan User admin seperti dibawah :

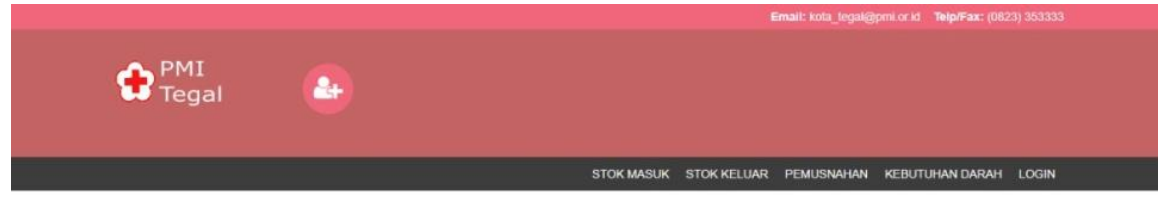

LOGIN PETUGAS ADMIN

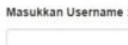

Masukkan Password:

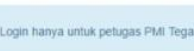

Gambar 2. Tampilan Halaman Login Petugas Admin 
Masukan Username admin dan Password admin lalu klik login nannti akan muncul tampilan beranda admin seperti dibawah :

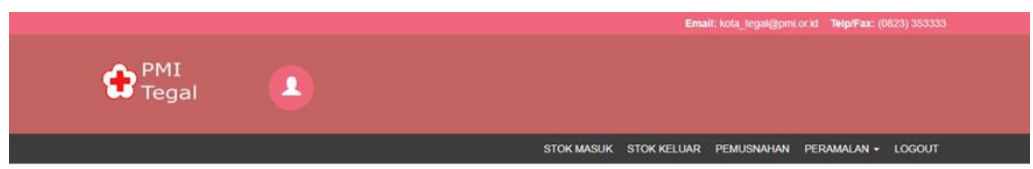

BERANDA ADMIN
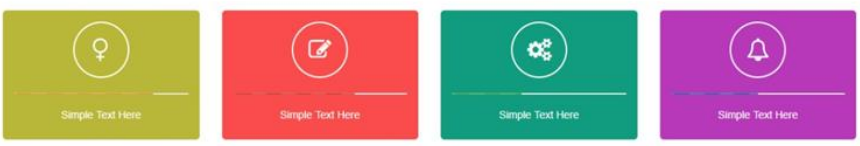

Gambar 3. Tampilan Halaman Beranda

2. Pilih menu "STOK MASUK" nanti akan muncul tampilan seperti dibawah :

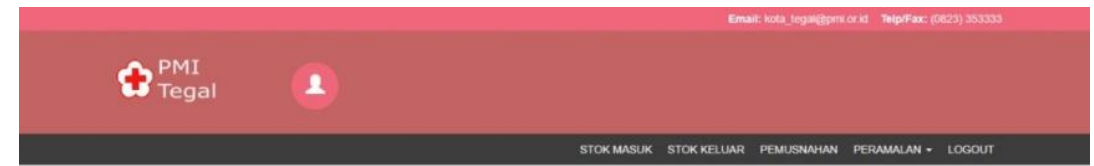

DATA STOK DARAH MaSUK

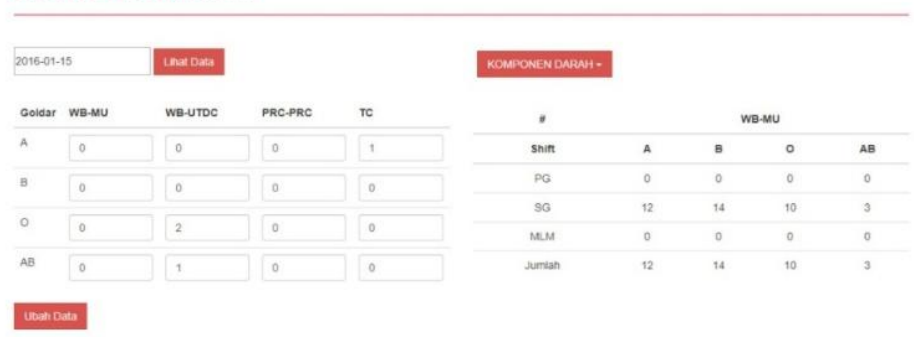

Gambar 4. Tampilan Halaman Data Stok Masuk

- Kemudian masukan tanggal yang akan diinput data, lalu pilih tombol 'Lihat Data'.

- Jika data pada tanggal yang dipilih sudah tersimpan akan muncul di tabel sebelah kanan layar .

- Lalu untuk memasukan data stok darah masuk form sebelah kiri layar sesuai golongan darah dan komponen darahnya.

- Jika data pada tanggal yang dipilih sudah pernah disimpan tombol di bawah form data stok darah masuk adalah tombol 'Ubah Data', sebaliknya jika belum tersimpan 
sama sekali tombol di bawah form data stok darah masuk adalah tombol 'Simpan Data'

- Pilih tombol 'KOMPONEN DARAH' di atas tabel sebelah kanan layar untuk beralih melihat dat stok darah sesuai komponen darah yang telah tersimpan.

- Langkah di atas juga sama atau berlaku pada saat memilih menu 'STOK KELUAR' dan PEMUSNAHAN .

3. Pilih menu 'PERAMALAN' dan pilih sub menu 'STOK KELUAR', lalu akan muncul tampilan seperti di bawah :

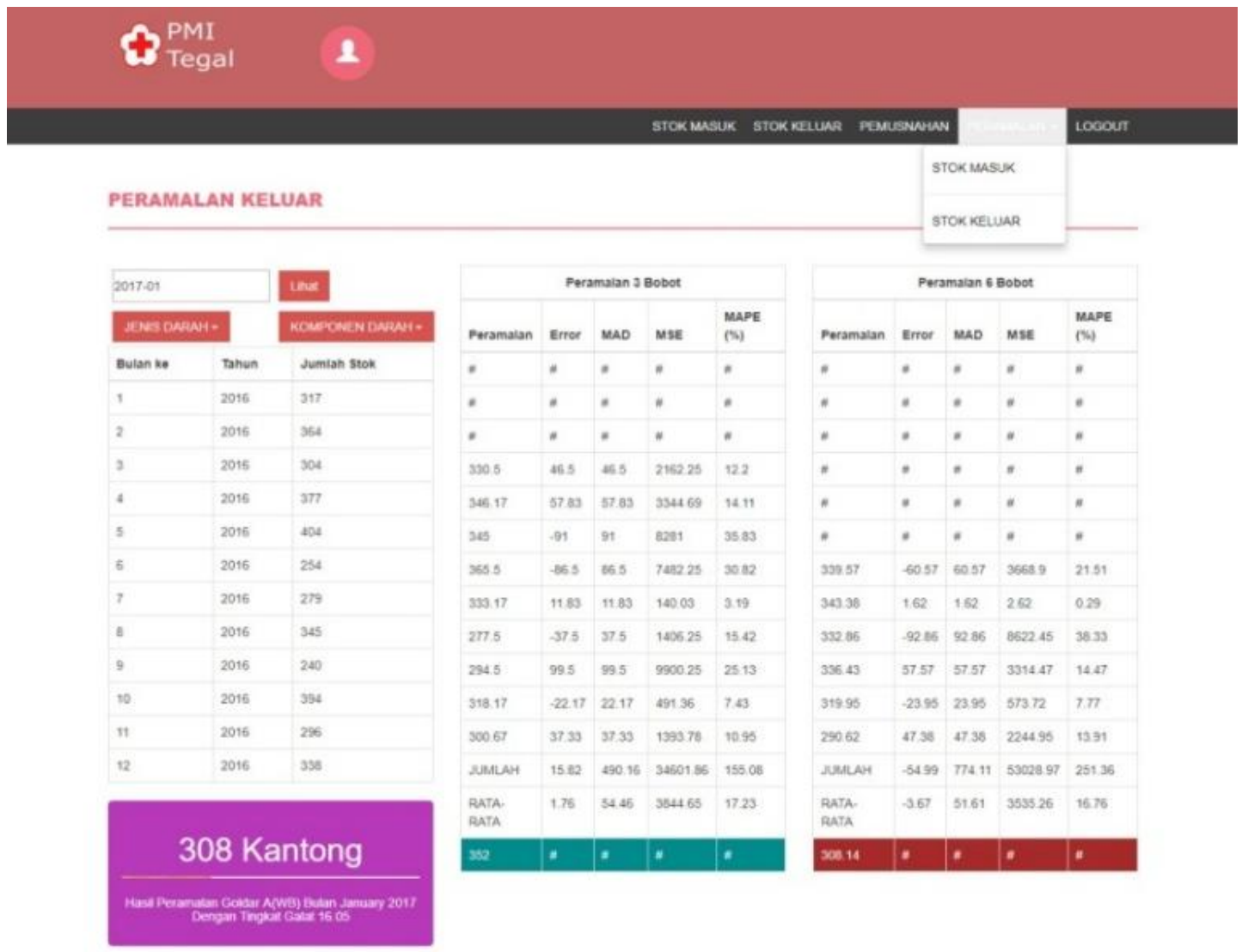

\section{Kesimpulan}

Gambar 4. Tampilan Halaman Peramalan Stok Darah Keluar

Berdasarkan uraian pembahasan pada bab-bab sebelumnya yang telah dibuat dan dirancang maka dapat diambil kesimpulan sebagai berikut :

1. Adanya pemodelan prediksi atau peramalan, maka dapat dibangun sistem peramalan yang dapat diterapkan, agar PMI dan/atau Masyarakat dapat mengetahui prakiraan jumlah stok darah satu bulan yang akan datang.

2. Melihat pemodelan pada bahasan diatas maka periode 6 bulan dipilih karena tingkat galat MSE dan/ atau MAPE terkecil, namun untuk diterapkan pada system peramalan, pemilihan periode bersifat dinamis tergantung kondisi stok darah di masa lalu. 
Saran yang dapat disampaikan untuk pengembangan sistem ke depan, adalah sebagai berikut :

1. Perlu data minimal 3 tahun untuk menghasilkan peramalan yang lebih baik.

2. Untuk penelitian ke depan, perlu pemilihan metode lain yang sejenis dan pengembangan metode WMA misal Exponential Weighted Moving Average agar lebih akurat dalam menghasilkan peramalan.

\section{Ucapan Terimakasih}

Ucapan terimakasih kepada kepala markas PMI kota Tegal dan Unit Transfusi Darah PMI kota Tegal beserta staff dan jajarannya juga unit P3M Politeknik Harapan Bersama Tegal serta semua pihak yang telah banyak memberikan bantuan dalam penyelesaian penelitian ini.

\section{Daftar Pustaka}

[1] Latifah, U., \& Triyono, R. A. (2013). Rancang Bangun Sistem Informasi Manajemen Pendonoran Darah Pada UDD PMI Kabupaten Pacitan. Speed-Sentra Penelitian Engineering dan Edukasi, 5(3).

[2] Utomo, K. B. (2016). Perancangan Sistem Informasi Bank Darah Hidup Untuk Mempercepat Penyediaan Calon Penyumbang Darah Dengan Ketepatan Yang Tinggi (Studi di PMI Kota Samarinda). Informatika Mulawarman: Jurnal Ilmiah Ilmu Komputer, 5(2), 22-28.

[3] Gofur, A. A. (2015). Sistem Peramalan Untuk Pengadaan Material Unit Injection di PT. XYZ. Komputa: Jurnal Ilmiah Komputer dan Informatika, 2(2).

[4] Sundari, S. S., Susanto, S., \& Revianti, W. (2015). Sistem Peramalan Persediaan Barang Dengan Weight Moving Average Di Toko The Kids 24. Proceedings Konferensi Nasional Sistem dan Informatika (KNS\&I).

[5] Pradibta, H., \& al Saffa, A. U. N. (2016). Pengembangan Sistem Informasi Penjualan dan Peramalan Jual Beli Menggunakan Metode Weighted Moving Average (Studi Kasus Toko Emas Maju Sari Kota Malang). Jurnal Informatika Polinema, 2(3), 138-138.

[6] Rossa, A. S., \& Shalahuddin, M. (2013). Rekayasa Perangkat Lunak. Bandung: Penerbit Informatika.

[7] Indrajani.(2015). Database Design. Jakarta: Elex Media Komputindo.

[8] Jogiyanto.(2005). Analisa \& Desain. Yogyakarta: Andi.

[9] Khadir, A., \& Triwahyuni, T. C. (2013). Pengantar teknologi informasi edisi revisi. Yogyakarta: CV Andi Offset.

[10] Mustaqbal M. Sidi dkk. (2015). Pengujian Aplikasi Menggunakan Back Box. Universitas Widyatama, Vol 1 (3), p 31-36.

[11] Sofiansah, T. (2013). Sistem informasi donor darah di Unit Donor Darah Palang Merah Indonesia Kota Bandung berbasis web. 